\title{
Modeling VOC-odor exposure risk in livestock buildings
}

\author{
Huang-Min Liang, Chung-Min Liao * \\ Department of Bioenvironmental Systems Engineering, National Taiwan University, Taipei, Taiwan 10617, ROC \\ Received 5 May 2006; received in revised form 17 December 2006; accepted 30 December 2006 \\ Available online 14 February 2007
}

\begin{abstract}
This paper describes a novel idea of linking models of exposure, internal dosimetry, and health effects. Risk assessment approach that integrates predicted odor caused by volatile organic compounds (VOC-odor) of toluene/xylene concentrations in human tissues leads to predict exposure risks in livestock buildings. First, VOC transport model was developed to calculate airborne toluene/xylene concentrations. Based on a physiologically based pharmacokinetic (PBPK) model, concentrations within five compartments representing lung, liver, fat, slowly perfused tissues, and rapidly perfused tissues could be quantified. By using a pharmacodynamic (PD) Hill model, we can optimally fit data from rat and human experiments to reconstruct dose-response relationships for accounting human health effects from nose poke and eye irritation. Results demonstrated that peak tissue concentration occurring at $5-10 \mathrm{~h}$ in that fat contains the highest concentration than other tissues at around $4 \mathrm{ppm}$ of toluene and $1.8 \mathrm{ppm}$ of xylene. The $\mathrm{EC}_{10}$ values are 114 and $232 \mathrm{ppm}$, whereas expected risks are estimated to be $0.71 \%$ and $0.26 \%$ of human exposure to toluene and xylene, respectively. Risk analyses indicate that inhalation exposure in livestock buildings poses no significant threat to human health under the present environmental conditions. This method provides a rigorous and effective approach to relate target tissue concentration to human nose poke or eye irritation. We suggest that our probabilistic framework and methods be taken seriously because they produce general conclusions that are more robust and could offer a risk-management framework for discussion of future establishment of limits for respiratory exposure to VOC-odor.
\end{abstract}

(c) 2007 Elsevier Ltd. All rights reserved.

Keywords: Toulene; Xylene; Probabilistic; Risk assessment; Physiologically based pharmacokinetic; Pharmacodynamic; Livestock building; VOC

\section{Introduction}

Epidemiological investigations of low-dose occupational exposures to toluene and xylene have reported apparent exposure concentration thresholds for increased risks (Eller et al., 1999; Ernstgard et al., 2003). Toluene and xylenes, two kinds of VOC-odor, typically arise from swine manure in livestock buildings (Liang and Liao, 2004). Xylenes exist in three isometric forms as ortho-, para-, and meta-dimethylbenzenes. VOC-odor concerns are mounting not only because they are a nuisance for local residents but also because they are an indicator that potential hazards are present. However, previous researches on human inhalation risk of toluene and xylene and the information on

\footnotetext{
* Corresponding author. Tel.: +88622363 4512; fax: +886223626433. E-mail address: cmliao@ntu.edu.tw (C.-M. Liao).
}

adverse health effects associated with long-term exposure in livestock buildings are seldom discussed.

Toxicity researches regarding inhalation exposure to toluene or xylene in humans include acute (Carpenter et al., 1975; Baelum et al., 1990) and chronic studies (Eller et al., 1999; Ernstgard et al., 2003). Neurological, reproductive and developmental tests are often documented through animal experiments (Wood and Cox, 1995; Ito et al., 2002). Acute toluene exposure by human inhalation causes irritation of the nose or eyes at $100 \mathrm{ppm}$ or greater (Baelum et al., 1990). Chronic exposure to low concentration of toluene causes impairment of the central nervous system (CNS) (Eller et al., 1999). Besides, the evidence confirms that xylene causes irritation of the eyes and upper respiratory tract, and has effects on many organ systems, including the CNS, liver, kidney, and hemopoietic tissues.

This manuscript presents a risk assessment for co-exposure to toluene and xylene based on published PBPK 
models to estimate internal dosimetry and correlating model predicted internal measures of dose with effects (sensory responses in human) using a Hill model. PBPK models describe the kinetics of toluene or xylene after inhalation exposure in humans (Tardif et al., 1995) and rats (Tardif et al., 1993). This approach represents the mammalian system in specific organs or groups of tissues lumped together by sets of mass balance differential equations. All of which are defined with respect to their intrinsic volumes, blood flow rates, partition coefficients and biochemical constants specific to the chemical under investigation. The PBPK models were then linked with transport model predicted inhalation concentrations of these chemicals in livestock buildings where toluene and xylene emanate from the manure of pigs. Then, health risks were predicted for exposure to toluene and xylene in livestock buildings.

Experiments with animals presume that animals are good surrogates for humans and that effects detected in animals will also occur in humans. Consequently, extrapolations from high to low doses and from lifetime exposures to short-term exposures in rodents have been used to estimate risks to humans (Kirman et al., 2003). All of these extrapolations to date have been undertaken by fitting data to statistical models with little regard to the biochemical and physiological processes underlying the biological responses.

The objectives of this study are threefold: (i) to describe human target-organ concentration-time profile in livestock exposure through integrating VOC transport and PBPK models; (ii) to use a pharmacodynamic (PD)-based Hill model to fit concentration-response relationships resulting from acute exposure regimes of animals and human volunteers to determine effect concentration; and (iii) to investigate the utility of the integrated PBPK/PD model in providing a physiological and mechanistic basis to the biological monitoring of toluene and xylene exposure risk in livestock buildings.

\section{Materials and methods}

\subsection{Problem formulation}

The flowchart of our study process to assess human exposure risk through integrating VOC transport model, PBPK model and PD model is shown in Fig. 1. The typical piggery with partially slatted floor is located in Tainan, southern Taiwan region. The section is $24 \mathrm{~m}$ long, $9.2 \mathrm{~m}$ wide and $2.5 \mathrm{~m}$ deep with a $30^{\circ}$ slope ceiling, and has similar insulation characteristics to a standard building. There are two manure pits of $1 \times 23 \mathrm{~m}^{2}$ on each side of the building. This pig housing has one negative pressure ventilation system and consisted of twelve compartments. Each compartment contains six pigs. The body weight of each growing pig is estimated to be $70 \mathrm{~kg}$. Indoor air temperature and relative humidity are measured to be $29 \pm 1.5^{\circ} \mathrm{C}$ and $65 \pm 3 \%$, respectively. We selected two intense and unpleasant VOC-odor, toluene and xylene, as study com- pounds. The environmental parameters and physiochemical properties of toluene and xylene are shown in Table 1.

Considering uncertainties of ventilation rate, manure moisture content, clean layer thickness, and contaminated layer thickness, and in analogy to the behavior assessment model of Jury et al. (1990), the VOC-odor flux at the stored swine manure surface, $J(t)$, can be expressed as follows (Liang and Liao, 2004):

$J(t)=C_{0} \mathrm{e}^{-\mu t}\left(\frac{D_{\mathrm{E}}}{\pi t}\right)^{1 / 2}\left\{\exp \left[-\frac{\left(L_{1}\right)^{2}}{4 D_{\mathrm{E}} t}\right]-\exp \left[-\frac{\left(L_{1}+L_{2}\right)^{2}}{4 D_{\mathrm{E}} t}\right]\right\}$,

in which $C_{0}$ is the initial concentration, $L_{1}$ is clean layer thickness, $L_{2}$ is contaminated layer thickness, and $D_{\mathrm{E}}$ is effective diffusion coefficient $\left(\mathrm{m}^{2} \mathrm{~s}^{-1}\right)$ that can be expressed as (see Table 1 for detailed symbol descriptions)

$D_{\mathrm{E}}=\frac{(\varepsilon-\theta)^{10 / 3} D_{\mathrm{a}} K_{\mathrm{H}}+\theta^{10 / 3} D_{\mathrm{w}}}{\varepsilon^{2}\left[\rho_{\mathrm{b}} f_{\mathrm{oc}} K_{\mathrm{oc}}+\theta+(\varepsilon-\theta) K_{\mathrm{H}}\right]}$.

The indoor VOC-odor concentration, $C(t)$, is obtained as

$C(t)=\frac{A}{Q} J(t)$,

where $A$ is manure surface area $\left(\mathrm{m}^{2}\right)$ and $Q$ is volumetric ventilation rate $\left(\mathrm{m}^{3} \mathrm{~s}^{-1}\right)$.

\subsection{Exposure analysis}

The PBPK model (Tardif et al., 1995) describing the pharmacokinetics of toluene or xylene is constructed for inhalation exposure (Fig. 1c) in that human body is subdivided into five compartments consisting of lung, liver, fat, slowly perfused tissues, and rapidly perfused tissues (see Appendix). A blood flow limitation to chemical flux at the tissue is assumed. Exchange of chemical across cellular membranes is rapid relative to transport of chemical by the blood from the various tissues. Each compartment is modeled as a well-stirred vessel represented by a mass balance differential equation relating input (arterial concentration of compound) to output (venous concentration leaving the tissue), incorporating compartment blood flows and volumes of distribution. Metabolism is limited to the liver compartment and is described as a saturated process characterized by a maximum velocity and an affinity constant.

The pharmacokinetic values of toluene and xylene for three types of parameters, that represent physiological, physiochemical and biochemical characteristics, are shown in Table 2 (Tardif et al., 1995). The tissue:blood partition coefficients required for human PBPK models are calculated by dividing the rat tissue:air values by the human blood:air values (Tardif et al., 1993). Evidence accumulated so far is suggestive of significant interspecies differences in blood:air partition coefficients of chemicals, whereas the tissue:air partition coefficients appear to be species-invariant. The biochemical parameters required for the PBPK modeling of toluene and xylene include $V_{\max }$, 


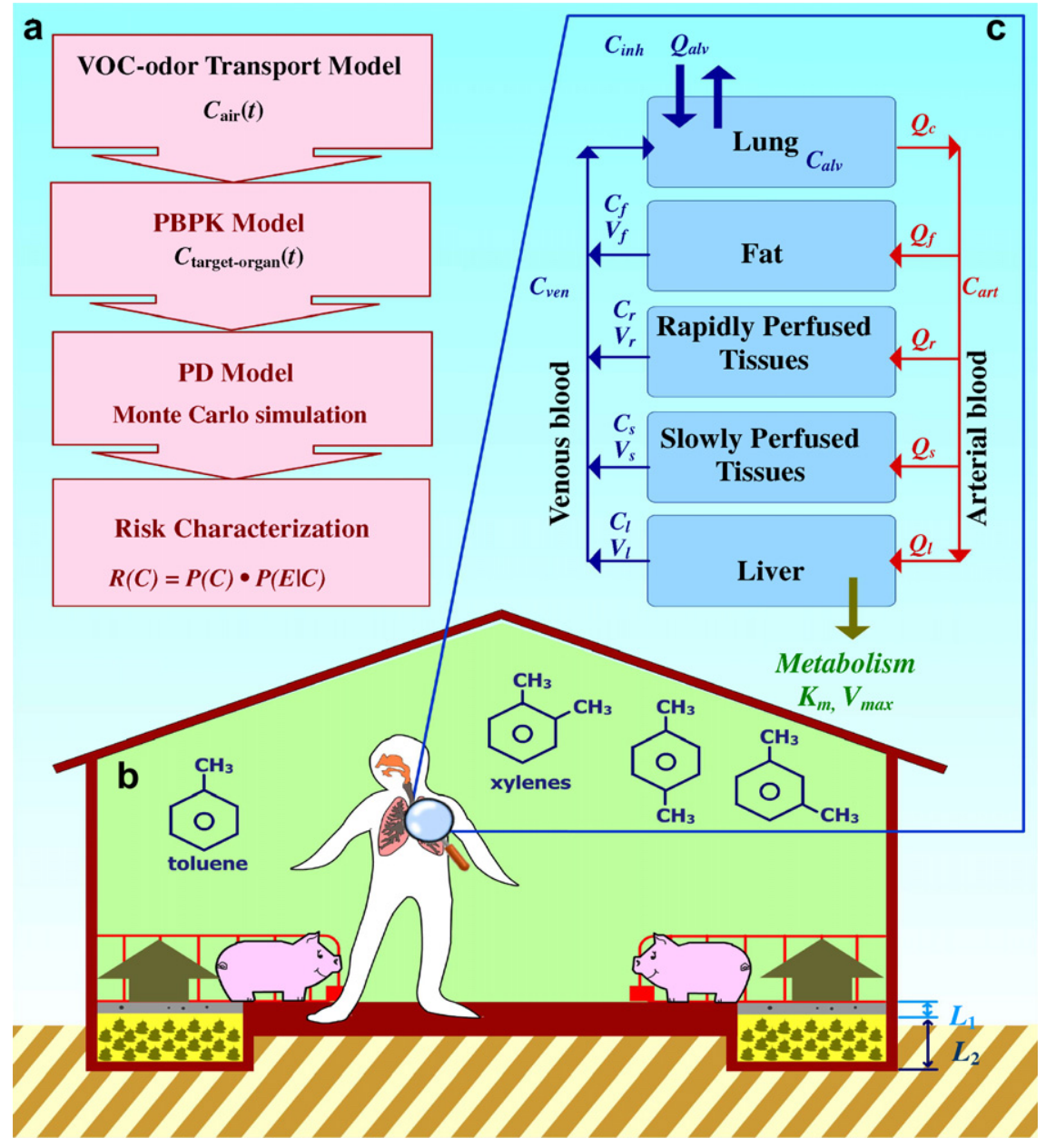

Fig. 1. (a) Flowchart of study process to assess human exposure risk through integrating VOC transport model, PBPK model, PD model and risk analysis; (b) the schematic of VOC-odor emission from manure to air in a livestock building; and (c) the representation of PBPK model in human (see Appendix).

Table 1

Manure parameters and physiochemical properties of toluene and xylene used for model implementation and Monte-Carlo simulations

\begin{tabular}{|c|c|c|c|c|}
\hline Property & Symbol & Value & & Units \\
\hline \multicolumn{5}{|l|}{ Manure parameters ${ }^{\mathrm{a}}$} \\
\hline Porosity & $\varepsilon$ & 90 & & $\%$ \\
\hline Moisture content & $\theta$ & $70 \pm 10$ & & $\%$ \\
\hline Organic carbon content & $f_{\mathrm{oc}}$ & 0.8 & & $\%$ \\
\hline Clean layer thickness & $L_{1}$ & $2 \pm 0.15$ & & $\mathrm{~cm}$ \\
\hline Contaminated layer thickness & $L_{2}$ & $8 \pm 4$ & & $\mathrm{~cm}$ \\
\hline Ventilation rate & $Q$ & $0.075 \pm 0.025$ & & $\mathrm{~m}^{3} \mathrm{~s}^{-1} \mathrm{pig}^{-1}$ \\
\hline Physiochemical properties & & Toluene & Xylene & \\
\hline Organic carbon distribution coefficient ${ }^{\mathrm{b}}$ & $K_{\mathrm{oc}}$ & 0.126 & 0.126 & $\mathrm{~m}^{3} \mathrm{~kg}^{-1}$ \\
\hline Henry's constant $\mathrm{c}^{\mathrm{c}}$ & $K_{\mathrm{H}}$ & 0.271 & 0.201 & Dimensionless \\
\hline Diffusion coefficient in air ${ }^{\mathrm{b}}$ & $D_{\mathrm{a}}$ & $8.8 \times 10^{-6}$ & $7.1 \times 10^{-6}$ & $\mathrm{~m}^{2} \mathrm{~s}^{-1}$ \\
\hline Diffusion coefficient in water ${ }^{\mathrm{d}}$ & $D_{\mathrm{w}}$ & $8.8 \times 10^{-10}$ & $7.1 \times 10^{-10}$ & $\mathrm{~m}^{2} \mathrm{~s}^{-1}$ \\
\hline
\end{tabular}

${ }^{\mathrm{a}}$ Values are adopted and estimated from Liang and Liao (2004).

b Values are adopted from Thibodeaux (1996).

${ }^{\mathrm{c}}$ Values are adopted from Weber and DiGiano (1995).

${ }^{\mathrm{d}} D_{\mathrm{w}}=D_{\mathrm{a}} \times 10^{-4}$ (Jury et al., 1990).

${ }^{\mathrm{e}}$ Values are adopted from Howard et al. (1991). 
Table 2

Physiological parameters, partition coefficients, and metabolic constants used in the human PBPK models for toluene and xylene ${ }^{\mathrm{a}}$

\begin{tabular}{|c|c|c|}
\hline Parameters & Toluene & Xylene \\
\hline \multicolumn{3}{|l|}{ Physiological parameters } \\
\hline Alveolar ventilation rate & 18.0 & 18.0 \\
\hline Cardiac output & 18.0 & 18.0 \\
\hline \multicolumn{3}{|l|}{ Fraction of total cardiac output } \\
\hline Fat & 0.05 & 0.05 \\
\hline Slowly perfused tissues & 0.25 & 0.25 \\
\hline Rapidly perfused tissues & 0.44 & 0.44 \\
\hline Liver & 0.26 & 0.26 \\
\hline \multicolumn{3}{|l|}{ Fraction of body weight } \\
\hline Fat & 0.19 & 0.19 \\
\hline Slowly perfused tissues & 0.62 & 0.62 \\
\hline Rapidly perfused tissues & 0.05 & 0.05 \\
\hline Liver & 0.026 & 0.026 \\
\hline \multicolumn{3}{|l|}{ Partition coefficients } \\
\hline Blood:air & 15.6 & 26.4 \\
\hline Fat:blood & 65.8 & 77.8 \\
\hline Slowly perfused tissues:blood & 1.37 & 3.0 \\
\hline Rapidly perfused tissues:blood & 2.66 & 4.42 \\
\hline Liver:blood & 2.98 & 3.02 \\
\hline \multicolumn{3}{|l|}{ Metabolic constants } \\
\hline$V_{\max }\left(\mathrm{mg} \mathrm{h}^{-1} \mathrm{~kg}^{-1}\right)$ & 4.8 & 8.4 \\
\hline$K_{\mathrm{m}}\left(\mathrm{mg} \mathrm{l}^{-1}\right)$ & 0.55 & 0.20 \\
\hline$K_{i}\left(\mathrm{mg} \mathrm{l}^{-1}\right)$ & 0.35 & 0.60 \\
\hline
\end{tabular}

a Values are adopted from Tardif et al. (1995).

$K_{\mathrm{m}}$, and metabolic inhibition constants. The determined $V_{\max }\left(\mathrm{mg} \mathrm{h}^{-1} \mathrm{~kg}^{-1}\right)$ in the study is converted to $V_{\max }$ $\left(\mathrm{mg} \mathrm{h}^{-1}\right)$ using the following allometric relationship: $V_{\max }$ $\left(\mathrm{mg} \mathrm{h}^{-1}\right)=V_{\max }\left(\mathrm{mg} \mathrm{h}^{-1} \mathrm{~kg}^{-1}\right) \times(\text { body weight })^{0.75}($ Krishnan and Andersen, 1991). This default approach has been successfully used with several individual chemicals (Tardif et al., 1995).

\subsection{Effect analysis}

When human data are sparse, especially data from chronic studies, animal data are used as a surrogate. An assessment of the risk to human health of exposure to toluene can be derived relying on animal studies. The acute behavioral effects of toluene were determined in 12 rats trained to nose poke on a probabilistic schedule of food delivery in a small exposure chamber that is highly ventilated with toluene concentration of 178,300 , and $560 \mathrm{ppm}$ for $2 \mathrm{~h}$ twice a week (Wood and Cox, 1995). The sensory response of xylenes was determined through inhalation of human volunteers with xylenes concentration of $110,230,460$, and $690 \mathrm{ppm}$ for $15 \mathrm{~min}$ exposure (Carpenter et al., 1975).

Proportion of animals affected by toluene (Wood and Cox, 1995) and human volunteers affected by xylenes (Carpenter et al., 1975) are both optimal fitted by a Hill model that is commonly used in PD modeling as (Lalonde, 1992)

$E=\frac{E_{\text {max }} C^{n}}{\mathrm{EC}_{\text {max }}^{/ 2 n}+C^{n}}$, where $C$ is the concentration in the recepor, $E_{\max }$ is the maximun dose effect, $\mathrm{EC}_{\max / 2}$ is the concentration that causes an equal effect to half of the $E_{\max }$, and $n$ is a slope factor referred to as the Hill coefficient.

\subsection{Risk characterization}

Reference concentration ( $\mathrm{RfC}$ ) developed by United States Environmental Protection Agency (USEPA) is typically used in quantifying risk of potential adverse human health effects from exposure to environmental chemicals. It can be expressed as follows (USEPA, 1994):

$\mathrm{RfC}=\frac{\text { NOAEL }}{F_{1} \times F_{2} \times F_{3}}$,

where NOAEL is no-observed-adverse-effect level. Since there is uncertainty in matching, we adjusted effect concentration from concentration-time profile by using uncertainty factors as indicated in Eq. (5),

$\mathrm{EC}_{\mathrm{a}}=\frac{\mathrm{EC}}{F_{1} \times F_{2} \times F_{3}}$,

where $\mathrm{EC}_{\mathrm{a}}$ is adjusted effect concentration, $\mathrm{EC}$ is effect concentration estimated from Hill model, $F_{1}$ and $F_{2}$ are uncertainty factors used to account for potential interspecies variation in response sensitivity and potential intraspecies variation in human sensitivity, and $F_{3}$ is uncertainty factor used when a lifetime or long-term EC is desired and only a short-term EC is available. Dourson and Stara (1983) had reviewed the historical and experimental bases for uncertainty factors.

Risk at a specific target organ concentration, $C$, can be calculated as the proportion of the group expected to have that tissue concentration multiplied by the conditional probability of ill effects, given concentration $C$. This results in a joint probability function or exceedance profile as

$R_{\mathrm{C}}=P(C) P(E \mid C)$,

where $R_{\mathrm{C}}$ is the risk at a specific concentration $C, P(C)$ is the probability of having tissue concentration $C$, and $P(E \mid C)$ is the conditional probability of the adverse effect, given tissue concentration $C$. The overall expected risk for a group might be computed as the sum of the risks for all possible concentrations as

$$
\begin{aligned}
R= & \int_{-\infty}^{\infty} \frac{1}{\sqrt{2 \pi} \sigma_{\mathrm{e}}} \\
& \times \exp \left[-\frac{1}{2}\left(\left(\log C-\mu_{\mathrm{e}}\right) / \sigma_{\mathrm{e}}\right)^{2}\right] P(E \mid C) \mathrm{d} \log C,
\end{aligned}
$$

where $\mu_{\mathrm{e}}$ and $\sigma_{\mathrm{e}}$ are mean and standard deviation of the log-transformed exposures, respectively; and $R$ is the estimated fraction of the group that is expected to suffer adverse effect.

\subsection{Uncertainty analyses}

Uncertainty arises from estimation of both exposure and effects. In order to quantify this uncertainty and its impact 
on the estimation of expected risk, we implement a Monte Carlo (MC) simulation that includes input distributions for the parameters of the derived concentration-response function as well as for estimated exposure parameters. Fifty thousand executions of the MC simulation are performed. A 95\% confidence interval (CI) for expected risk is determined on the basis of the 2.5 th and 97.5 th quantiles of the simulation results. A risk curve is generated from the cumulative distribution of simulation outcomes. The simulation is implemented using Crystal Ball ${ }^{\circledR}$ (Version 2000, Professional Edition, Decisioneering, Inc., UK).

\section{Results}

\subsection{Exposure assessment}

The predicted pattern of toluene is qualitatively similar to that observed from xylene (Fig. 2). By incorporating input parameters (Table 2) into pharmacokinetic models (Appendix), toluene concentration ratios of tissue:air could be found as $0.06,0.05,3.4,0.07$, and 0.14 for lung, liver, fat, slowly perfused tissues, and rapidly perfused tissues to air toluene concentration, respectively, whereas xylene concentration ratios of tissue:air are $0.05,0.01,2.2,0.087$, and 0.12 for lung, liver, fat, slowly perfused tissues, and rapidly perfused tissues to air xylene concentration, respectively. The results show that fat contains the highest concentration at around $4 \mathrm{ppm}$ of toluene and $1.8 \mathrm{ppm}$ of xylene occurring approximately $5-10 \mathrm{~h}$ in livestock building and declining thereafter. Values calculated for liver are somewhat lower than those of other tissues. This may have been due to metabolic clearance. The concentration-time profiles show that both toluene and xylene distributed at different rates into lung, liver, fat, slowly perfused tissues, and rapidly perfused tissues, and achievement of peak concentration occur in the order of fat,
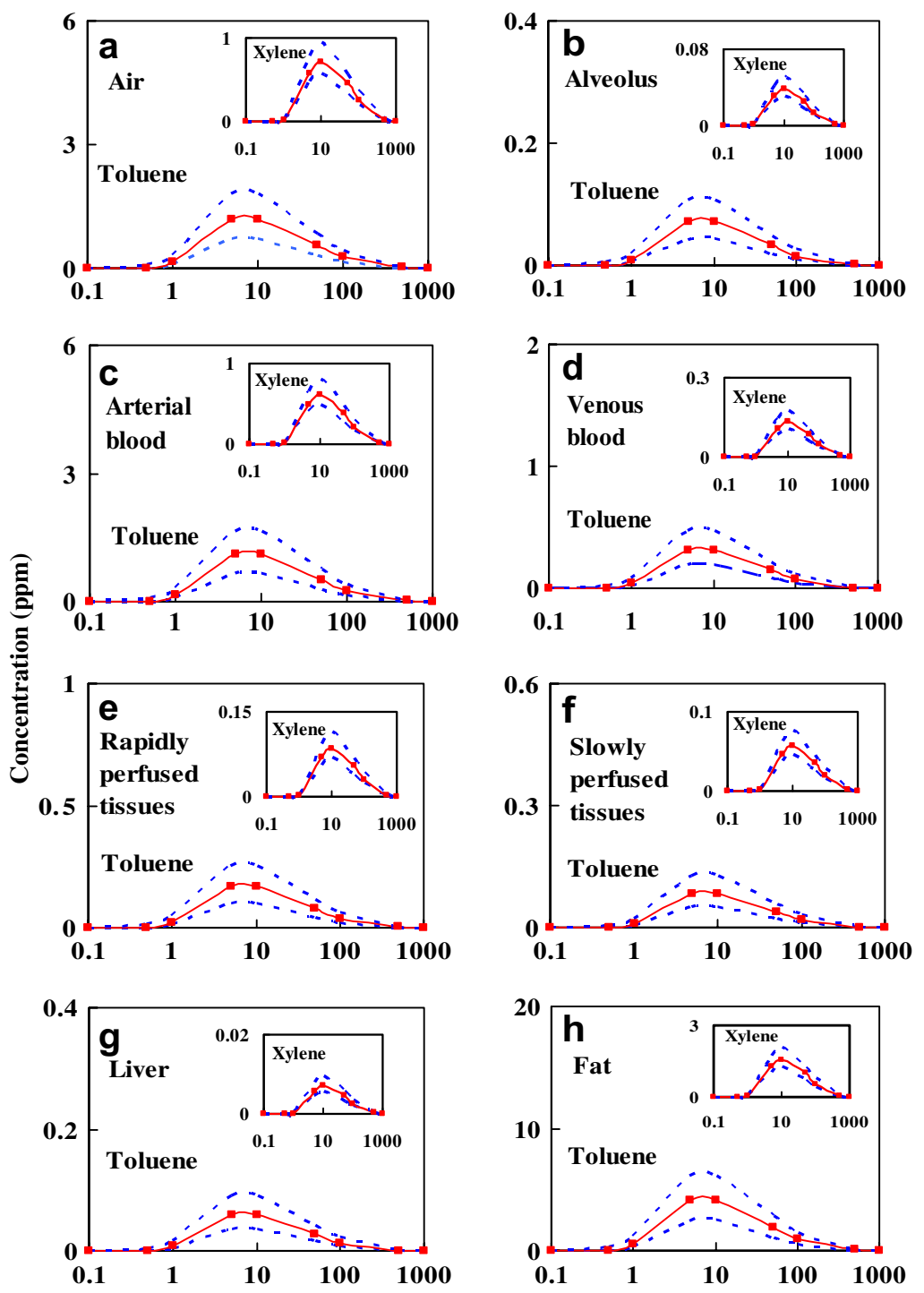

Time (h)

Fig. 2. Model predictions of toluene and xylene with 95\% confidence interval (dashed lines) in: (a) air, (b) alveolus, (c) arterial blood, (d) venous blood, (e) rapidly perfused tissues, (f) slowly perfused tissues, (g) liver, and (h) fat from VOC transport model and PBPK model. 
rapidly perfused tissues, slowly perfused tissues, lung, and liver.

Applying the $\mathrm{MC}$ technique to the proposed exposure model generated probabilistic estimates of VOC-odor concentration in human (Fig. 3). The toluene or xylene concentration in human is estimated from target organ/tissue concentration $\times$ each compartment fraction of whole body weight. Probabilistic simulations of the PBPK model produce skewed distributions of predicted toluene and xylene concentrations in human (Fig. 3). An overlap exists between toluene concentrations in the air and human from 0.73 to $1.17 \mathrm{ppm}$. Whereas probability density functions of xylene concentration in the air and human only have a significant overlap at near $0.52 \mathrm{ppm}$ (Fig. 3a and b). The medians of toluene concentrations are 1.12 and $0.87 \mathrm{ppm}$, whereas those of xylene concentrations are 0.71 and $0.38 \mathrm{ppm}$ in the air and human, respectively (Fig. 3c).

\subsection{Concentration-response assessment}

Regressions are performed on the number of animals having significant increases in rates of responding at toluene concentrations of 178 (4/12 affected), 300 (9/12 affected), and $560 \mathrm{ppm}$ (12/12 affected) (Wood and Cox,
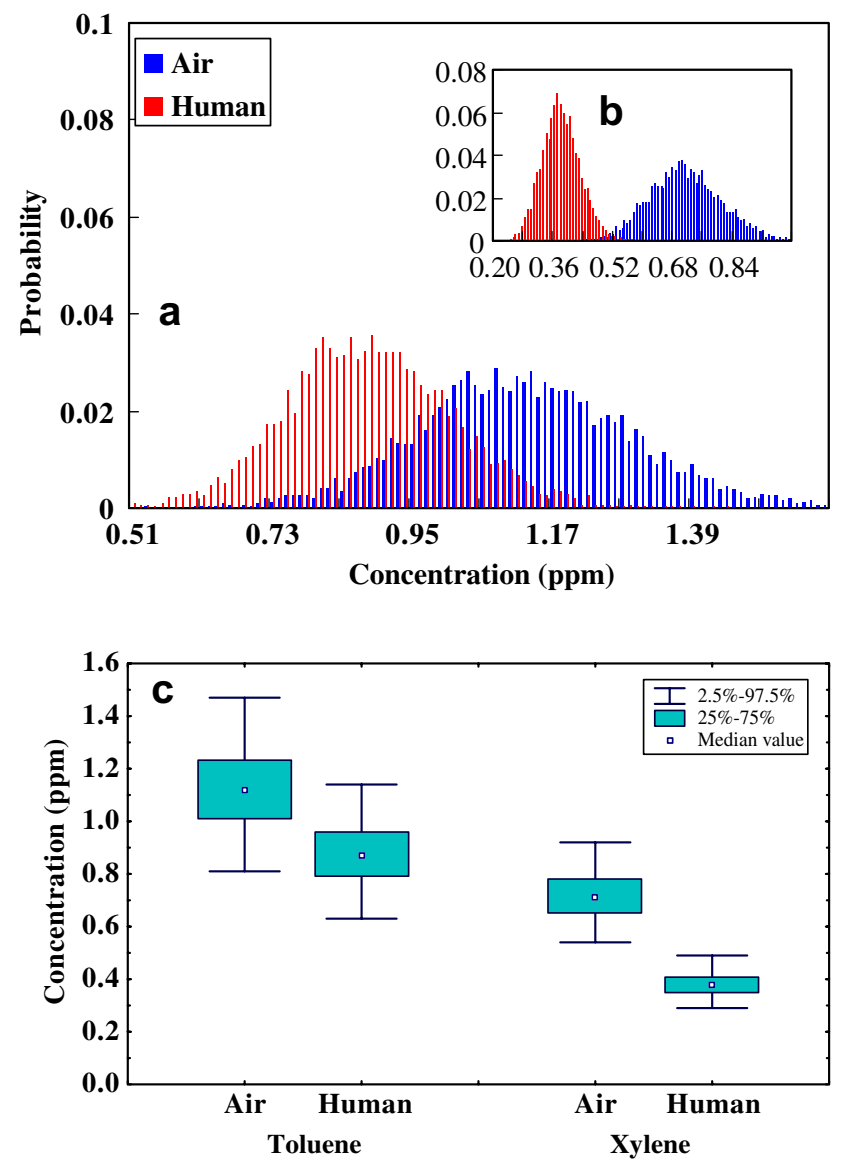

Fig. 3. Probabilistic density functions predicted from: (a) toluene and (b) xylene concentrations in the air and human, and (c) box and whisker plot of toluene and xylene concentrations in air and human.
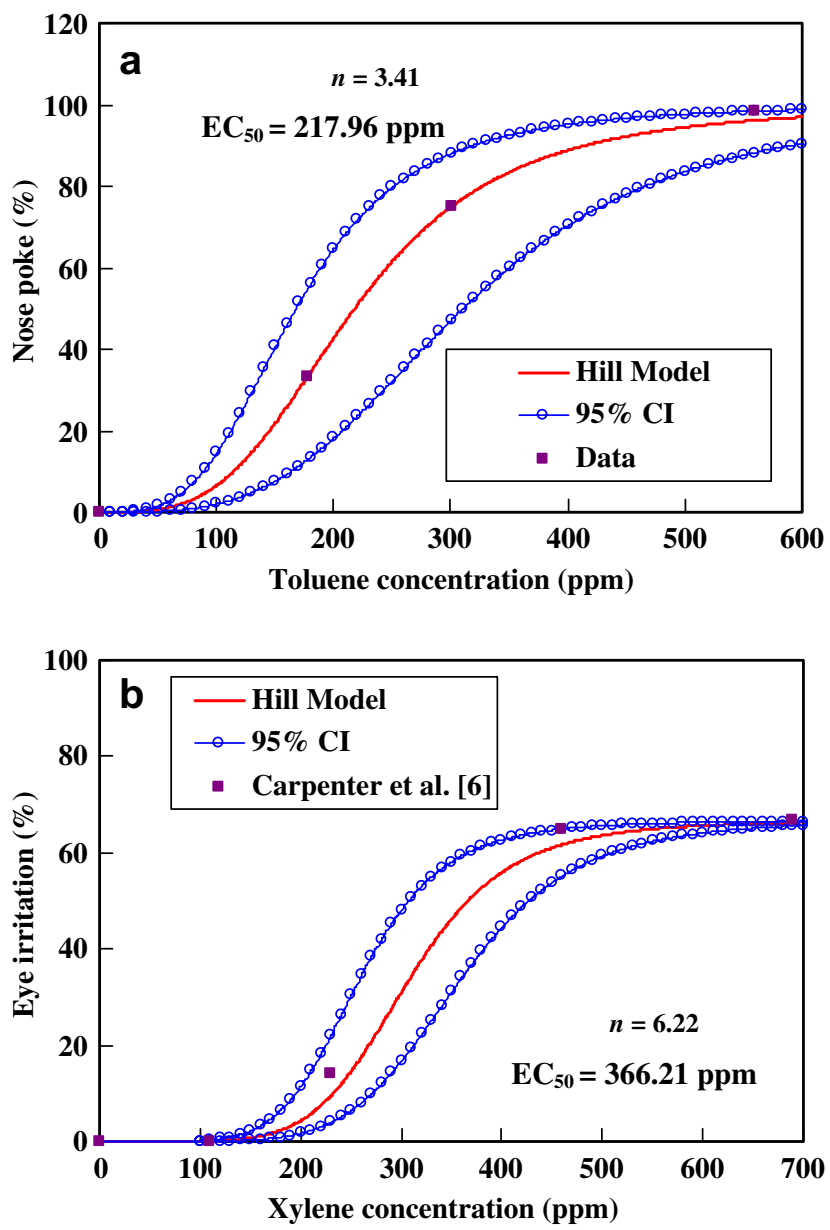

Fig. 4. Reconstructed concentration-response curve with 95\% confidence interval of: (a) toluene and (b) xylene that are optimal fitted by Hill model.

1995) (Fig. 4a) and on the number of human volunteers having significant eye irritation effect at xylene concentrations of 230 (1/7 affected), 460 (4/6 affected), and $690 \mathrm{ppm}$ (4/6 affected) (Carpenter et al., 1975) (Fig. 4b). The Hill model and a $5000 \mathrm{MC}$ simulation provide an adequate fit for the data ( $\chi^{2}$ goodness-of-fit, $P>0.05$ ). The calculated median effective concentration $\left(\mathrm{EC}_{50}\right)$ of toluene was $217.96 \mathrm{ppm}(95 \% \mathrm{CI}: 166.24-309.86 \mathrm{ppm})$ and $\mathrm{EC}_{50}$ of xylene was $366.21 \mathrm{ppm}$ (95\% CI: $306.57-425.86 \mathrm{ppm})$. The estimated Hill coefficients $(n)$ obtained from optimal fitting by nonlinear regression are 3.41 for toluene and 6.22 for xylene. The $\mathrm{EC}_{10}$ values (at which $10 \%$ of the animals are affected), a surrogate threshold of regulatory endpoint in probabilistic ecological risk assessment (USEPA, 2000), calculated from the fitted concentration-response model were 114 for toluene and $232 \mathrm{ppm}$ for xylene.

\subsection{Risk estimates and sensitivity analysis}

In applying extrapolation of human toluene effect concentration from animal experiment, we consider uncertainty factor $F_{1}=10$ for potential interspecies variation, and $F_{3}=10$ for deriving a long-term EC from acute expo- 


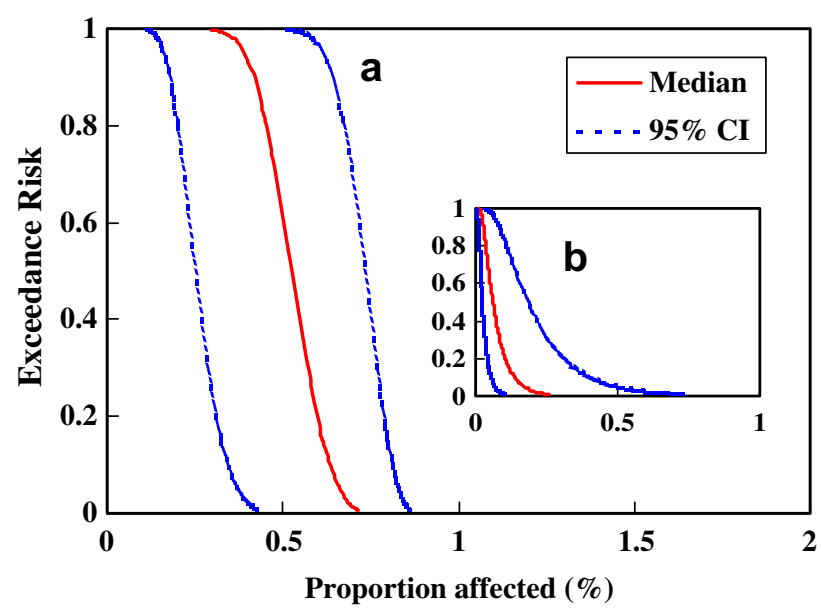

Fig. 5. Exceedance risk functions with $95 \%$ confidence interval for: (a) toluene and (b) xylene.

sure test. Adjusted effect concentraion of xylene only considers $F_{3}=10$ for deriving a long-term EC from short-term data (USEPA, 1994). Risk curves (Fig. 5) indicate that the probability that $10 \%$ or more of human would be affected (risk $=0.1$ ) is approximately $0.64 \%$ of human exposure to toluene would suffer nose poke, with $95 \%$ CI of $0.35 \%$ and $0.81 \%$, i.e., the probability is 0.1 which means that at least $0.64 \%$ of human in livestock would suffer nose poke. Furthermore, the probability that $5 \%$ or more of human would be affected (risk $=0.05$ ) is approximately $0.17 \%$ of human exposure to xylene would suffer eye irritation, with $95 \% \mathrm{CI}$ of $0.07 \%$ and $0.49 \%$. These ranges represent the uncertainty in expected risk estimates with both the inherent variability and uncertainty in exposure, and concentration-response parameter estimates are considered.

Sensitivity analysis is performed to determine which input variables have the greatest impact on the VOC-odor concentration for identifying critical control points, which is one of the important steps in the hazard analysis. Sensitivity analysis indicates that the correlation coefficients of ventilation rate, manure moisture content, clean layer thickness, and contaminated layer thickness are -0.66 , $0.51,-0.32$, and 0.22 , respectively. Furthermore, the contributions to variance of ventilation rate, manure moisture content, clean layer thickness, and contaminated layer thickness are $51.2 \%, 30.9 \%, 12 \%$, and $5.9 \%$, respectively.

\section{Discussion}

\subsection{Comparison of effect concentration with reference concentration}

A previous chronic toluene inhalation $\mathrm{RfC}$ of $0.11 \mathrm{ppm}$ (USEPA, 1992) was calculated based on the lowestobserved-adverse-effect level (LOAEL) of $88 \mathrm{ppm}$ for decreased performance in neurological tests with occupational exposed females (Foo et al., 1990) with an uncertainty factor of $300(10,10$ and 3 -fold are used to account for intraspecies variability, use of LOAEL and data base deficiencies). However, Zavalic et al. (1998) derived $\mathrm{RfC}$ for toluene as $1.15 \mathrm{ppm}$, which is 10 times higher than the previous study. Chronic xylene inhalation $\mathrm{RfC}$ of $0.16 \mathrm{ppm}$ is calculated based on $5.1 \mathrm{ppm}$ for critical effects of eye irritation, sore throat, floating sensation, and poor appetite from 175 xylene-exposed factory workers and control population of 241 factory workers (Uchida et al., 1993) with an uncertainty factor of 30 is used to account for LOAEL (3-fold) and intraspecies variability (10-fold). Compare the threshold values estimated by Hill model with $\mathrm{RfC}$, indicating that the $\mathrm{EC}_{10}$ values are 1.14 and $23.2 \mathrm{ppm}$, whereas RfCs are 1.15 and $0.16 \mathrm{ppm}$ for toluene and xylene, respectively, due to the determination of uncertainty factors.

The ranges of uncertainty factor reflect the variety of $\mathrm{RfC}$ for different chemicals and exposure durations. If the default 3-fold uncertainty factor for RfC is used for experimental animal to human extrapolation, we may wonder whether the 10 -fold factor is sufficient to protect human health for those animal-based RfC for which human data are lacking to corroborate the nature of concentrationresponse pattern of the critical effect. Besides, whether the public's health is protected if one excludes the use of human-based RfC and uses instead those on animal data. When RfC is based upon no-effect levels from human rather than animal data, an animal-to-human uncertainty factor (usually 10) is not required, which could conceivably result in a higher safe exposure limit.

\subsection{Implications}

Although toluene and xylene may have effects on many organ systems, including the CNS, liver, kidney, eyes, upper respiratory tract and hemopoietic tissues, however, critical effects of target organs (CNS, kidney, or liver) versus concentration during human inhalation exposure periods are not available for fitting by Hill model. Due to the lack of significant concentration-response data over a wide range of concentrations, eye irritation and nose poke effect have been chosen as the critical endpoints. Furthermore, both effects occur at low levels after short-term exposure. The consideration of data on a number of different life stages and organ systems at each of those life stages may affect the size of the uncertainty factor used to account for variability within humans. The development and use of mode of action information is extremely important, particularly in how it can be used for extrapolation to humans, as well as to support a linear or nonlinear approach for low dose extrapolation.

The limitation of the current model is its complexity. The model includes detailed descriptions for many processes that are important only for certain classes of chemicals, but the inclusion of these detailed process descriptions increases the data demands and computer running times for all model applications. We have demonstrated that it is both desirable and feasible to develop 
mechanistic PBPK models that are flexible in their empiricism and accuracy.

Our analysis indicates no significant threat of human health exposure to toluene and xylene in livestock buildings under the present environmental conditions. We specifically chose to quantify adverse effects related to VOC-odor exposure and toxicological data from experiments strongly supporting the choice of toluene and xylene as study compounds to carry out risk assessment. Furthermore, if the concentrations of some VOCs are uncharacteristically high for site-specific livestock buildings, the possibility of a significantly increased risk uncounted for by our model should be investigated.

\section{Appendix}

\section{PBPK model}

The physiological model is described mathematically by a set of simultaneous differential equations to quantify the rate of change of toluene or xylene within each tissue group. Pulmonary uptake and elimination of toluene or xylene are described by an algebraic expression for the mass balance of VOC-odor entering and leaving the lungs. The metabolism of toluene or xylene is described by Michaelis-Menten type expression for saturated metabolism in the liver tissue group. (1) Lung compartment: in the lung compartment, toluene or xylene input to the lung occurs via inhaled air and venous blood, while output occurs via exhaled alveolar air and arterial blood and can be expressed by the following equation:

$Q_{\text {alv }}\left(C_{\text {inh }}-C_{\text {alv }}\right)=Q_{\mathrm{c}}\left(C_{\text {art }}-C_{\text {ven }}\right)$,

where $Q_{\text {alv }}$ represents blood perfusion of alveolar, $Q_{\mathrm{c}}$ represents blood perfusion of cardiac output, $C_{\text {inh }}$ is the inhaled concentration, $C_{\text {alv }}$ is the alveolar concentration, $C_{\text {art }}$ is the arterial concentration, $C_{\text {ven }}$ is the venous concentration, and $N=C_{\text {art }} / C_{\text {alv }}$ is blood/air partition coefficient. Mass balance across the lung yields

$C_{\mathrm{art}}=\frac{Q_{\mathrm{alv}} C_{\mathrm{inh}}+Q_{\mathrm{c}} C_{\mathrm{ven}}}{Q_{\mathrm{c}}+Q_{\mathrm{alv}} / N}$.

By assuming that alveolar respiration accounts for $70 \%$ of total respiration, the vapor concentration in exhaled air is given by $C_{\text {exh }}=0.7 C_{\text {alv }}+0.3 C_{\text {inh }}$ where $C_{\text {exh }}$ represents exhaled concentration. (2) Tissue concentration: The rate of change of toluene or xylene in tissue groups is described by the blood flow rate to the tissue group $\times$ the difference in VOC-odor concentration between arterial and venous blood. Tissue concentrations are expressed by the following set of equations:

$V_{i} \frac{\mathrm{d} C_{i}}{\mathrm{~d} t}=Q_{i}\left(C_{\mathrm{art}}-C_{v i}\right)=Q_{i}\left(C_{\mathrm{art}}-C_{i} / P_{i}\right)$,

where $Q_{i}, C_{i}$ and $V_{i}$ represent blood flow, concentration and volume of a given organ " $i$ ", which are denoted by c, for cardiac output, s, for the slowly perfused tissues, r, for the rapidly perfused tissues, $f$, for the fat compartment, and 1 , for the liver compartment, respectively. $P_{i}$ stands for a blood:tissue partition coefficient. (3) Liver metabolism: metabolism rate was described by Michaelis-Menten type of equation. Liver concentration was shown as follows:

$V_{1} \frac{\mathrm{d} C_{1}}{\mathrm{~d} t}=Q_{1}\left(C_{\mathrm{art}}-C_{1}\right)-\frac{V_{\max } C_{1}}{K_{\mathrm{m}}+C_{1}}$,

where $V_{\max }$ is the maximum metabolism rate, $K_{\mathrm{m}}$ is the substrate concentration which gives the half maximum rate of metabolism describing saturable enzymic metabolism. (4) Venous return: the concentration of toluene or xylene in mixed venous blood returning to the lungs is described by the sum of the venous contribution from each of the four tissue groups as shown by

$C_{\mathrm{ven}}=\frac{\sum Q_{i} C_{i}}{Q_{\mathrm{c}}}$.

\section{References}

Baelum, J., Lundqvist, G.R., Molhave, L., Andersen, N.T., 1990. Human response to varying concentrations of toluene. International Archives of Occupational and Environmental Health 62, 65-71.

Carpenter, C.P., Kinkead, E.R., Geary Jr., D.L., Sullivan, L.J., King, J.M., 1975. Petroleum hydrocarbon toxicity studies: V. Animal and human response to vapors of mixed xylenes. Toxicolology and Applied Pharmacology 33, 543-558.

Dourson, M.L., Stara, J.F., 1983. Regulatory history and experimental support of uncertainty (safety) factors. Regulatory Toxicology and Pharmacology 3, 224-238.

Eller, N., Netterstrom, B., Laursen, P., 1999. Risk of cronic effects on the central nervous system at low toluene exposure. Occupational Medicine 49, 389-395.

Ernstgard, L., Sjogren, B., Warholm, M., Johanson, G., 2003. Sex differences in the toxicokinetics of inhaled solvent vaporsin humans: I. m-xylene. Toxicology and Applied Pharmacology 193, 147-157.

Foo, S.C., Jeyaratnam, J., Koh, D., 1990. Chronic neurobehavioural effects of toluene. British Journal of Industrial Medicine 47, 480-484.

Howard, P.H., Boethling, R.S., Jarvis, W.F., Meylan, W.M., Michalenko, E.M., 1991. Handbook of Environmental Degradation Rates. Lewis, Michigan, p. 366, 410, 643.

Ito, T., Yoshitome, K., Horike, T., Kira, S., 2002. Distribution of inhaled $m$-xylene in rat brain and its effect on $\operatorname{GABA}(\mathrm{A})$ receptor binding. Journal of Occupational Health 44, 69-75.

Jury, W.A., Russo, D., Streile, G., Abd, H.E., 1990. Evaluation of volatilization by organic chemicals residing below the soil surface. Water Resource Research 26, 13-20.

Kirman, C.R., Sweeney, L.M., Meek, M.E., Gargas, M.L., 2003. Assessing the dose-dependency of allometric scaling performance using physiologically based pharmacokinetic modeling. Regulatory Toxicology and Pharmacology 38, 345-367.

Krishnan, K., Andersen, M.E., 1991. Interspecies scaling in pharmacokinetics. In: Rescigno, A., Thakkur, A.K. (Eds.), New Trends in Pharmacokinetics. Plenum Press, New York, pp. 203-226.

Lalonde, R.L., 1992. Pharmacodynamics. In: Evans, W.E., Schentag, J.J., Jusko, W.J. (Eds.), Applied Pharmacokinetics. Lippincott Williams and Wilkins, New York, pp. 4-1-4-33.

Liang, H.M., Liao, C.M., 2004. Dynamic transport of livestock generated VOC-odor in a ventilated airspace with mixing heterogeneity. Atmospheric Environment 38, 345-355.

Tardif, R., Lapare, S., Charest-Tardif, G., Brodeur, J., Krishnan, K., 1995. Physiologically-based pharmacokinetic modeling of a mixture of toluene and xylene in humans. Risk Analysis 15, 335-342. 
Tardif, R., Lapare, S., Krishnan, K., Brodeur, J., 1993. Physiologically based modeling of the toxicokinetic interaction between toluene and $\mathrm{m}$ xylene in the rat. Toxicology and Applied Pharmacology 120, 266-273.

Thibodeaux, L.J., 1996. Environmental Chemodynamics. Wiley, New York, pp. 554-558.

US Environmental Protection Agency, 1992. Integrated Risk Information System (IRIS). Environmental Criteria and Assessment Office, Office of Health and Environmental Assessment, Cincinnati, OH.

US Environmental Protection Agency, 1994. Methods for Derivation of Inhalation Reference Concentrations and Application of Inhalation Dosimetry. EPA/600/8-90/066F: Office of Research and Development, Washington, DC.

US Environmental Protection Agency, 2000. Technical Progress Report of the Implementation Plan for Probabilistic Ecological Assessments:
Aquatic Systems. Meeting Scheduled for April 6-7, 2000, Washington, DC.

Uchida, Y., Nakatsuka, H., Ukai, H., Watanabe, T., Liu, Y.T., Huang, M.Y., Wang, Y.L., Zhu, F.Z., Yin, H., Ikeda, M., 1993. Symptoms and signs in workers exposed predominantly to xylenes. International Archives of Occupational and Environmental Health 64, 597-605.

Weber, W.J., DiGiano, F.A., 1995. Process Dynamics in Environmental Systems. Wiley, New York, pp. 321-422.

Wood, R.W., Cox, C., 1995. Repeated-measures approach to the detection of the acute behavioral-effects of toluene at low concentrations. Fundamental and Applied Toxicology 25, 293-301.

Zavalic, M., Mandic, Z., Turk, R., Bogadi-Sare, A., Plavec, D., 1998. Quantitative assessment of color vision impairment in workers exposed to toluene. American Journal of Industrial Medicine 33, 297-304. 